\title{
Study of the Anisotropy of the Roller Compacted Concrete (RCC) for Pavement
}

\author{
Mustapha Zdiri, ${ }^{1,2)}$ Nor-edine Abriak, ${ }^{2)}$ Mongi Ben Ouezdou, ${ }^{1)}$ and Jamel Neji ${ }^{3)}$
}

(Received September 17, 2009, Revised April 30, 2010, Accepted April 30, 2010)

\begin{abstract}
The roller compacted concrete (RCC) is supposed to be isotropic, whereas the compaction of this material, which is achieved using the same machines used for the soil, appears only unidirectional, making the RCC an anisotropic material. In this experimental work, the influence of the phenomenon of compaction on the isotropy of the RCC is studied. This study was carried out through an evaluation of the compressive strengths and ultrasonic tests which were used for measurements of the elastic modulus and the dynamic Poisson's ratio of the RCC as well as a qualitative judgement of the RCC aspect at the hardened state. The results of this work proved the anisotropy of the RCC and they showed the sensitivity of the mechanical strengths and the elastic modulus to the compaction direction.
\end{abstract}

Keywords : roller compacted concrete (RCC), vibro-compaction, anisotropy, strength, elastic modulus.

\section{Introduction}

The isotropy is defined when the material presents the same physical and mechanical properties in all the directions taken around an unspecified point of its mass. Based on this fundamental definition, the Roller Compacted Concrete (RCC) seems to be an isotropic material. But the method of implementation by compaction of this material, which differs from that of the Conventional Concrete (CC), leads to wonder about the isotropy of this material and to seek and identify this intrinsic property of the RCC mixture.

The RCC employed as a construction material in the base or course roadways, must show the best characteristics. In a fresh state, it behaves like a soil not compacted. The compaction of the $\mathrm{RCC}$ is identical to the compaction of a soil or a gravel layer in pavement. The main objective is to reduce the volume of the interstices in this material and to prevent the resulting slow compaction and settlement under the loads. The second objective is to carry out a preventive action by anticipating these deformations before the putting into operation of the roadways. ${ }^{1}$

The vibrator rollers are generally used for the compaction of the RCC implemented in pavement. And to model this type of compaction in the laboratory, we used the mode of Vibro-compaction which includes the combination of the vibrations using a vibrating table and the pressure of a load placed directly on the surface of the RCC. By this manner, the concrete is confined in all the direc-

\footnotetext{
${ }^{1)}$ Civil Engineering Laboratory, National Engineering School of Tunis, Tunis-Belvédère 1002, Tunisia. E-mail: zdiri_ms@yahoo.fr. ${ }^{2)}$ Laboratoire de Génie Civil et Environnemental Ecole des Mines de Douai, rue Charles Boursel BP 838-59508 France.

${ }^{3)}$ Applied Mechanics and Systems Research Laboratory Polytechnic School of Tunis, Tunisia.

Copyright (c) 2010, Korea Concrete Institute. All rights reserved, including the making of copies without the written permission of the copyright proprietors.
}

tions and its segregation is thus limited. ${ }^{2}$ The operation of RCC compaction is achieved in practice by the technique of Vibro-compaction. This compaction is carried out along only one direction and the edges can be or not confined. The material obtained is in a sufficiently compacted state and it must present suitable mechanical characteristics in all the directions since the strength tests are generally made along only one direction.

The objective of this paper is to study the RCC isotropy on an experimental basis. It includes consequently an evaluation of the RCC strength along several directions of loading. It includes also the measurements of the elastic modulus and the dynamic Poisson's ratio using the ultrasonic tests as well as a qualitative judgement of the RCC aspect in a hardened state.

\section{Preparation of the mixtures and the specimens}

\subsection{The used materials}

Based on the various aggregates beforehand identified, the authors considered four mixtures obtained by combination of the two types of sand: siliceous and limestone, and of the two different gravel structures and gradation (d/D in mm) 4/16 and 0/20. The binder that is used is hydraulic cement Portland type CEM ${ }^{2}$ II/C-L 32.5 and had a relative density equal to $3,029 \mathrm{~kg} / \mathrm{m}^{3}$. Characteristics and data relative to these aggregates are presented in Table 1 and Fig. 1.

For the formulation of these mixtures, the authors employed the Compressible Packing Model, developed at "Laboratoire Central des Ponts et Chaussées en France (LCPC)."3 Through the software "Rene LCPC," the percentages of the various components were determined. The components of the four mixtures are presented in the Table 2.

\subsection{Densification of the RCC}

At the exit of the mixer, the RCC behaves like a slightly wet 
Table 1 Characteristics of aggregates.

\begin{tabular}{c|c|c|c|c|c}
\hline Aggregates & Type & Source & Relative density $\left(\rho \mathrm{kg} / \mathrm{m}^{3}\right)$ & Los Angeles & Flatting ratio $(\%)$ \\
\hline \hline Sand Kh & Rolled sand 0/5 & Khelidia $^{(1)}$ & 2,575 & - & - \\
\hline Sand JO & Crushed sand 0/5 & Djebel Ouest $^{(1)}$ & 2,530 & - & - \\
\hline Gravel 4/16 & Crushed gravel 4/16 & Djebel El-Ressas $^{(1)}$ & 2,650 & 28.30 & 19.37 \\
\hline Gravel 0/20 & Crushed gravel 0/20 & Djebel El-Ressas $^{(1)}$ & 2,631 & 26.50 & 25.58 \\
\hline${ }^{(1)}$ Quarries in the North of Tunisia.
\end{tabular}

Table 2 Constituents of the used aggregates mixtures (\%).

\begin{tabular}{c|c|c|c|c|c|c}
\hline No. & Mixture & Cement & Sand Kh & Sand JO & Gravel 0/20 & Gravel 4/16 \\
\hline \hline M1 & Sand Kh and Gravel 0/20 & 11.22 & 26.628 & & 62.132 & - \\
\hline M2 & Sand JO and Gravel 0/20 & 11.22 & - & 26.634 & 62.146 & - \\
\hline M3 & Sand Kh, Sand JO and Gravel 4/16 & 11.22 & 22.500 & 21.915 & - & 44.415 \\
\hline M4 & Sand Kh, Gravel 4/16 & 11.22 & 35.528 & - & - & 53.292 \\
\hline
\end{tabular}

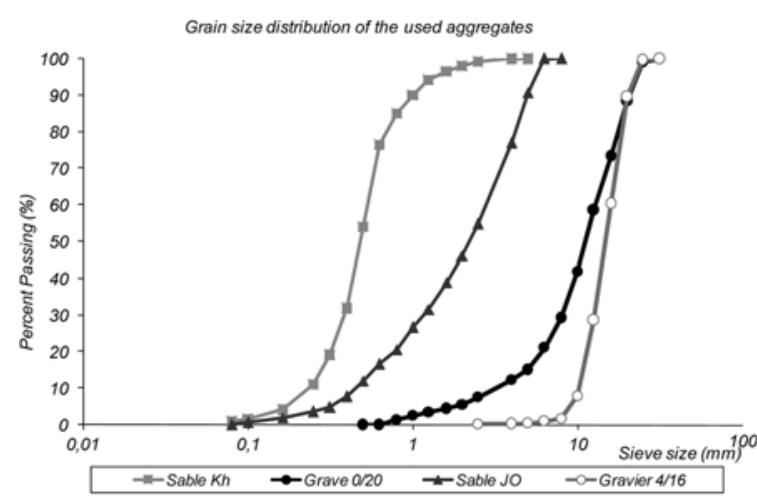

Fig. 1 Grain size distribution of the used aggregates.

soil. To obtain a high "bearing capacity," this material should be compacted, i.e. to reach the best arrangement of the grains, which gives the maximum density. To model the compaction in the laboratory, the mode of Vibro-compaction is used which includes the combination of the vibrations using a vibrating table and the pressure of a load placed vertically on the surface of the RCC. By this way, the concrete is confined in all directions and its segregation is thus limited. ${ }^{1}$ The objective of the vibration is to reach a compact configuration. Moreover the distribution and the layout of the coarse aggregates represent high importance. The vibration was applied in a uniform way to all the mass and on all RCC surfaces.

\subsection{The specimen set-up}

In this study, the method of Vibro-compaction was used. The vibration frequency was fixed at $50 \mathrm{~Hz}$. This method of compaction allows the placement of very dry concretes as it is the case of the RCC, because the vibration was supplemented by a compression of $6.5 \mathrm{kPa}$ of the applied load. ${ }^{5}$

The confection of the specimens is made according to the method of the National French Project BaCaRa. ${ }^{5}$ They were released from the mould after 24 hours and they were conserved in water at a temperature of about $20^{\circ} \mathrm{C}$ and relative humidity more than $95 \%$.

\section{Study of the RCC anisotropy through the compression test}

\subsection{Compression test on the cube specimens}

In this study, the authors examined the breaking of the roller compacted concrete (RCC) and the conventional concrete (CC)

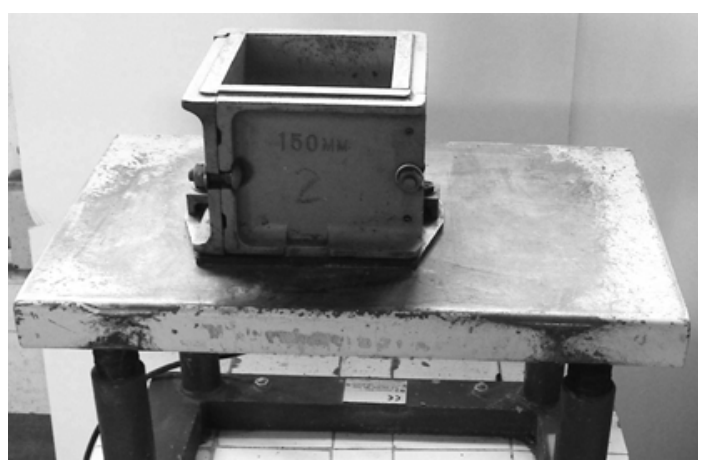

Fig. 2 Vibro-compaction by the vibrating table.

specimens subjected to a uniaxial compression. The compression tests by centred compression were made on a compression machine "type form-test" of capacity $3,000 \mathrm{kN}$. The tests were carried out after 28 days of conservation in water.

During the test, the cubes were placed parallel or at a right angle referred to its position of implementation. This configuration allows obtaining three different facets of the cubic specimen corresponding to the three principal directions (Figs. 3 and 4).

Position 1 is that corresponding to the facet $\mathrm{F} 1$ which is parallel to the superposition of the layers of the RCC implementation. Positions 2 and 3 are those corresponding to the facets F2 and F3 which are perpendicular to the superposition of the layers of the implementation.

Figure 3 shows and explains how the facet F1 is parallel to the position implementation. The facets $\mathrm{F} 2$ and F3 are placed at right angle compared to the position of implementation and compaction of the RCC. The same tests were achieved for the CC specimens.

During the compression tests, the load was applied vertically and the edges of the cubic specimens must not only be plane, but also perpendicular to the longitudinal axis, which guarantees their

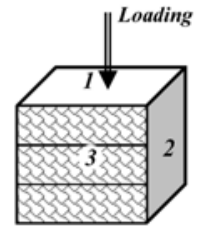

On Facet Fl

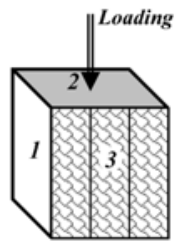

On Facet F2

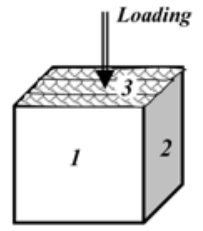

On Facet F3
Fig. 3 Representation of the three facets of a tested RCC specimen. 


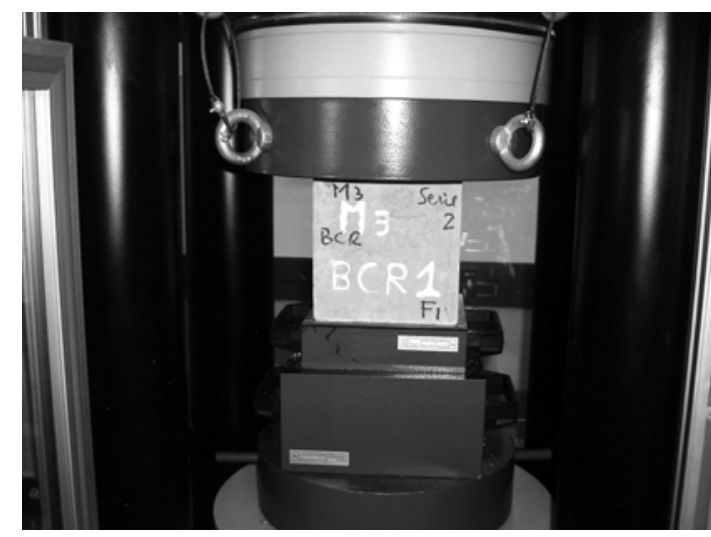

Fig. 4 Compression of the RCC specimen according to one of the three various facets.

parallelism. The specimen was placed on the press and its axis is practically confused with that of the press. The correct alignment of the horizontal facets is obtained by a spherical knee joint of the machine.

\subsection{Results and discussion}

The results of the compressive strengths of the RCC cubes of $150 \times 150 \times 150 \mathrm{~mm}$ for three different facets F1, F2 and F3 of the specimens and for each mixture explained in Table 2, are presented on Fig. 5. The results of the compression of the conventional concrete $(\mathrm{CC})$ cubes of $150 \times 150 \times 150 \mathrm{~mm}$ are summarized on the Fig. 6.

The principal interpretations are summarized as follows:

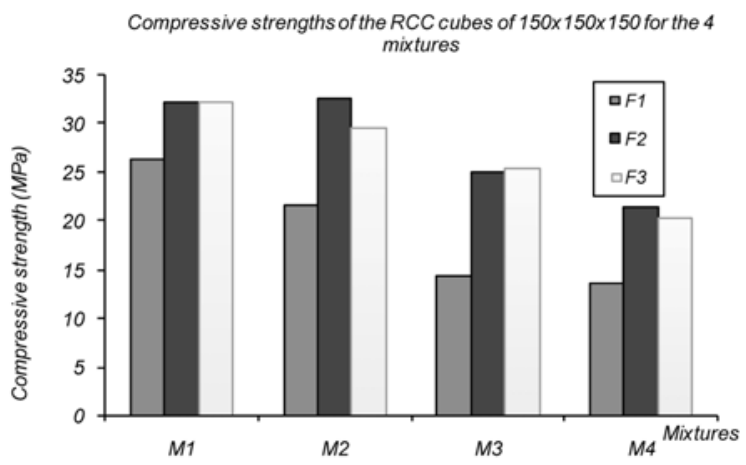

Fig. 5 Compressive strengths of the RCC cubes of $150 \times 150$ $\mathrm{x} 150 \mathrm{~mm}$ for the 4 mixtures.

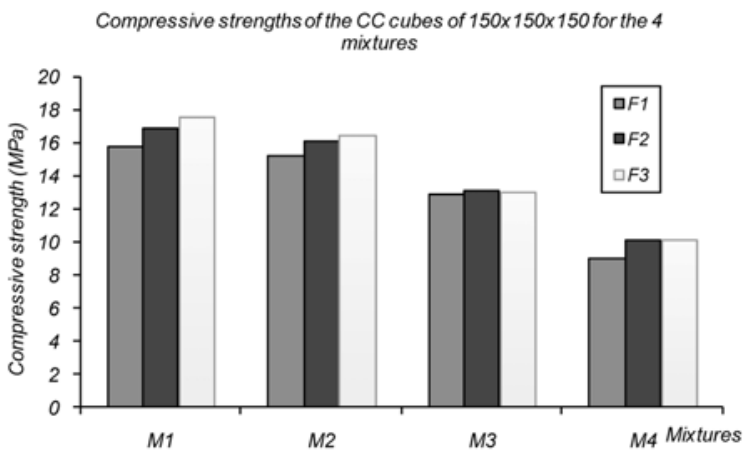

Fig. 6 Compressive strengths of the CC cubes of $150 \times 150$ $x 150 \mathrm{~mm}$ for the 4 mixtures.
- On Fig. 5, the values of the compressive strengths on cubes $150 \times 150 \times 150 \mathrm{~mm}$ for the $4 \mathrm{RCC}$ mixtures measured on the facets F2 and F3 are clearly higher than the values of the measured on the facet F1. This difference varies from $22 \%$ for the mixture M1 to $75 \%$ for the mixture M3.

- Fig. 5 shows consequently that the RCC is strongly influenced by the phenomenon of Vibro-compression (vibration + pressure).

- Fig. 6 presents the values of the compressive strengths for the 4 mixtures of the $\mathrm{CC}$, measured on the facets $\mathrm{F} 2$ and $\mathrm{F} 3$ which are close to those measured on the facet F1. Because the $\mathrm{CC}$ is not too affected by the phenomenon of vibration and the positions of the coarse aggregates is aleatory dispersed and does not follow a privileged direction.

\subsection{The RCC aspect in the hardened state}

The arrangement state of the aggregates and the RCC surface is related to several factors. The superposition and the inter-granular connection as well as the surface quality of the RCC can vary, more or less, according to the methods and the direction of the compaction. This analysis performed through the aspect of the broken specimens' surface. Such surface is presented in Fig. 7, which show that the coarse aggregates are arranged horizontally parallel to the layers of the RCC implementation. These layouts follow a privileged direction because it is influenced by the effect of the load pressure and the vibration.

For the test on the facet F1, the compressed aggregates are mostly arranged horizontally. Their breaking by bending is easier than in vertical disposition (F2 and F3).

For the test on the facets F2 and F3, the compressed aggregates are arranged so that their rupture is more difficult since it appears by crushing and not by bending.

Moreover the operations of implementation, limiting or supporting the segregation, influence also the arrangement and the texture of this material.

\section{Study of the RCC anisotropy through the measurements of the elastic modulus}

In this part, the static and dynamic elastic modulus is studied. The dynamic elastic modulus is obtained through ultrasonic testing of the RCC specimen. The principle consists in measuring the propagation velocity of the waves through cubic specimen of RCC. The static elastic modulus is deduced from the dynamic modulus through existing models. ${ }^{6}$

The sonic apparatus used allows us to measure the propagation

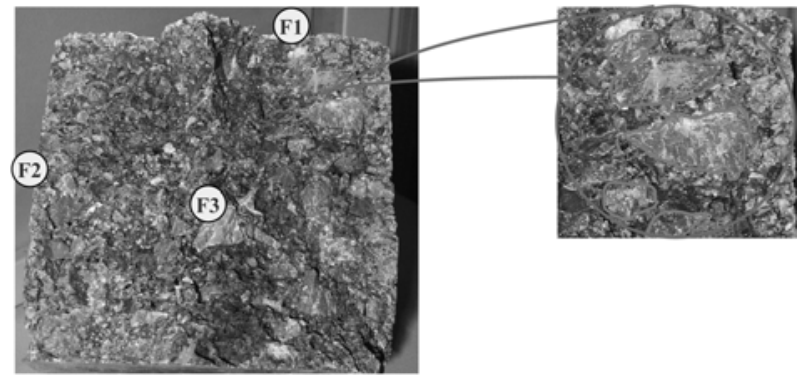

Fig. 7 Section showing the arrangement of the coarse aggregates in a broken RCC specimen. 
velocity of the ultrasonic waves $V$ through cubic samples of RCC $(150 \times 150 \times 150 \mathrm{~mm})$ placed between a transmitter and a receiver (Fig. 8).

The determination of the dynamic elastic modulus Ed was made by ultrasonic measurements using the "Ultrasonic apparatus type Test standard 58-E0049." Using this device, ten measurements of the wave velocity, were taken for each facet. To get the average results only height measurements were considered by removing the smallest and the largest value. The dynamic modulus can be given by the following relation:

$$
E_{d}=\rho \times V_{L}^{2} \times \frac{(1+v)(1-2 v)}{(1-v)}
$$

With $\rho$ is the RCC density $\left(\mathrm{kg} / \mathrm{m}^{3}\right), V_{L}$ is the measured velocity of the wave $(\mathrm{m} / \mathrm{s})$, and $v$ is the Poisson's ratio of the RCC taken as 0.22 . $^{7}$

The static elastic modulus $\mathrm{E}_{\mathrm{c}}$ is predicted from the dynamic elastic modulus $\mathrm{E}_{\mathrm{d}}$. Several empirical relations were proposed by authors for this prediction. The most suitable for the RCC is the following Eq. (2), which is formulated by Lydon and Balendran. 6,7

$$
E_{c}=0.83 \times E_{d}
$$

Measurement tests of elastic modulus are made on cubic specimen placed according to three different positions F1, F2, and F3 as previously identified (section 3-1)

Table 3 presents the results of an example of an ultrasonic test on an RCC cubic specimen.

Fig. 9 presents a summary of results of the ultrasonic tests on the series of four RCC mixtures measured on the three facets F1, $\mathrm{F} 2$ and $\mathrm{F} 3$.

\section{Interpretations:}

- For the 4 mixtures, as shown in Fig. 9, a difference is noticed

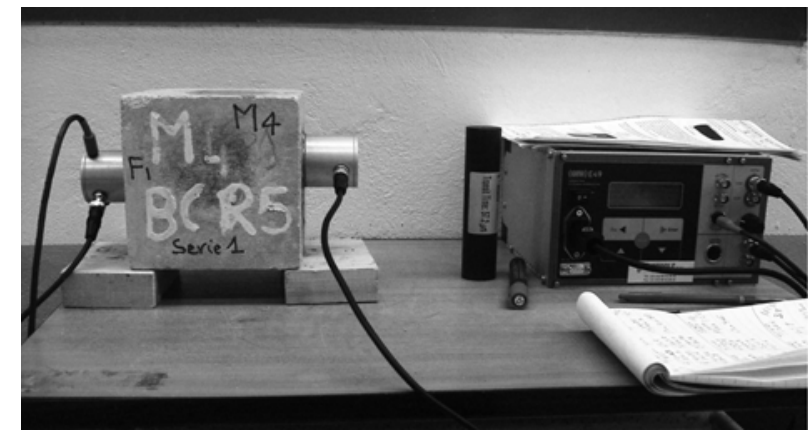

Fig. 8 Ultrasonic equipment for the measurement of elastic modulus of the RCC.

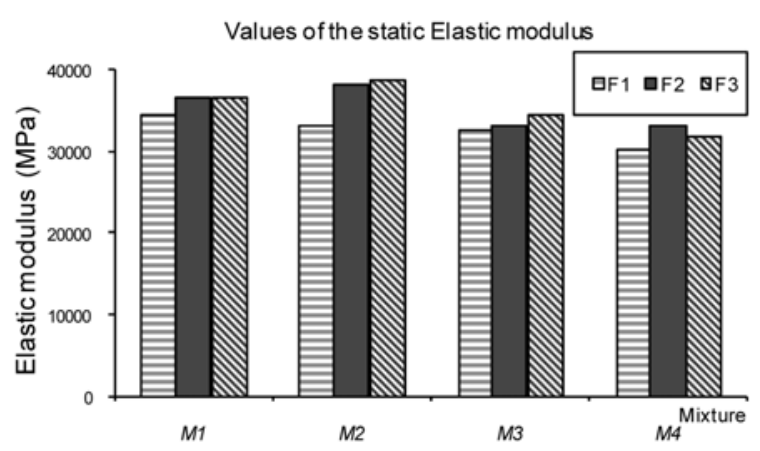

Fig. 9 Elastic modulus of the RCC on cubes $150 \times 150 \times$ $150 \mathrm{~mm}$ for 4 mixtures.

between the static elastic modulus measured by the ultrasonic method on the facet F1 and the elastic modulus measured on the other facets F2 and F3. This difference varies between $1 \%$ for the case of the mixture M3 and 15\% for the case of the mixture M2.

- The static elastic modulus measured on the facets F2 and F3 are almost equal especially for the mixtures M1 and M3 but they are always higher than the measured modulus on the facet F1. The difference is due probably to the manner of arrangement of the coarse aggregates in the mould by effect Vibro-compaction.

\section{Study of the RCC anisotropy through the measurements of dynamic Poisson's ratio}

When the RCC specimens are subjected to oscillations, longitudinal elastic waves and transverse waves are obtained. The longitudinal elastic waves are useful for the determination of the dynamic modulus and the transverse waves enable us to determine the dynamic Poisson's ratio. These transverse waves are employed while placing the sensor under transverse incidence. The propagation velocity of these waves is indicated by $V_{T}$.

Figure 10 shows the measuring method by placing the trans-

Table 3 Example of values of the RCC elastic modulus on a cubic $150 \times 150 \times 150 \mathrm{~mm}$ specimen.

\begin{tabular}{c|c|c|c|c|c|c|c|c|c|c|c}
\hline Measure No. & 1 & 2 & 3 & 4 & 5 & 6 & 7 & 8 & 9 & 10 & Average \\
\hline \hline $\mathrm{L}(\mathrm{mm})$ & 1,500 & 1,500 & 1,500 & 1,500 & 1,500 & 1,500 & 1,500 & 1,500 & 1,500 & 1,500 & 1,500 \\
\hline $\mathrm{V}(\mathrm{m} / \mathrm{s})$ & 4,582 & 4,582 & 4,491 & 4,739 & 4,841 & 4,727 & 4,841 & 5,131 & 5,031 & 4,803 & 4,770 \\
\hline $\mathrm{t}(\mu \mathrm{s})$ & 32.7 & 32.7 & 33.4 & 31.6 & 31 & 31.7 & 31 & 29.2 & 29.8 & 31.2 & - \\
\hline $\mathrm{V}(\mathrm{km} / \mathrm{s})$ & 4.582 & 4.582 & 4.491 & 4.739 & 4.841 & 4.727 & 4.841 & 5.131 & 5.031 & 4.803 & 4.77 \\
\hline $\mathrm{Ed}$ & $42,295.22$ & $42,295.22$ & $40,631.91$ & $45,243.32$ & $47,211.88$ & $45,014.49$ & $47,211.88$ & $53,037.75$ & $50,990.55$ & $46,473.59$ & $45,837.18$ \\
\hline $\mathrm{E}_{\mathrm{c}}=0.83 \times \mathrm{E}_{\mathrm{d}}(\mathrm{MPa})$ & 35,105 & 35,105 & $33,724.5$ & 37,552 & $39,185.9$ & 37,362 & $39,185.9$ & $44,021.3$ & $42,322.2$ & $38,573.1$ & $38,044.85$ \\
\hline
\end{tabular}




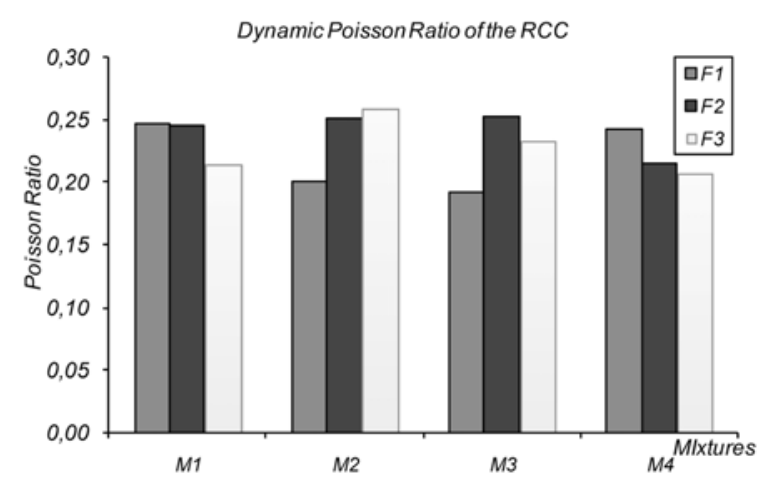

Fig. 11 Results of dynamic Poisson's ratio of the RCC on cubes $150 \times 150 \times 150 \mathrm{~mm}$ for 4 mixtures

ducer on the specimen facets. Figure 11 presents, the results of the measurements of the dynamic Poisson's ratio on a series of 4 mixtures measured on the three facets F1, F2 and F3.

\section{Interpretations:}

The value of the dynamic Poisson's ratio of the RCC mixture differs from a facet to another. Figure 11 shows that the difference between the dynamic Poisson's ratio measured on the facet F1 and the dynamic Poisson's ratio measured on the other facets F2 and F3 varies between $14 \%$ for the case of the mixture M4 and 30\% for the case of the mixture M2. This difference is probably due also to the manner of arrangement of the coarse aggregates in the mould by Vibro-compaction effect. However this difference does not follow the law of variation defined during the measurement of the elastic modulus of the RCC.

\section{Comparison between the RCC and the CC results}

According to these experimental measurements, the difference between the values of the compressive strengths on RCC cubes $150 \times 150 \times 150$ measured according to the various facets varies from $22 \%$ to $75 \%$ whereas this difference does not exceed $12 \%$ for the case of the values of the CC strength.

This difference is explained by the fact that in the implementation phase of the RCC on building site or in the laboratory, the technique of Vibro-compaction, used to compact this material, comprises the application of a vertical load simultaneously with a vibration. The vibration causes effect of fluidize to the mixture. The internal friction is decreased and allows the coarse aggregates to be placed. The load is responsible of the orientation of the coarse aggregates. They will be laid generally in flat position perpendicular to the direction of the load. This arrangement modifies the mechanical characteristic and makes the RCC an anisotropic material

Moreover, for the Compaction of the $\mathrm{CC}$, only the vibration, for which the amplitude is lower compared to that applied for the RCC, was applied. For this reason the phenomenon of anisotropy is higher in the RCC than in the CC.

\section{Conclusions}

Based on this study, we can conclude that the RCC material contains, in general, many vacuums. Its resistance is low and some settlements can occur under the action of the loads. To obtain a good strength and "bearing pressure," this material should be compacted. It's deduced that the RCC is an anisotropic material according to the following observations:

1) The compressive strengths on cubes of $150 \times 150 \times 150 \mathrm{~mm}$ for the 4 RCC mixtures measured on the facets F2 and F3 which are perpendicular to the superposition of the layers of the implementation are clearly higher than those on the facet $\mathrm{F} 1$ parallel to the superposition of the layers of the RCC implementation

2) The static elastic modulus measured on the facets F2 and F3 are almost equal especially for the mixtures M1 and M3 but they are always higher than the measured modulus on the facet F1.

3) For the 4 RCC mixtures, the values of the dynamic Poisson's ratio recorded on the facet $\mathrm{F} 1$ were always different to those in the facets F2 and F3 which present comparable values but clearly lower or higher than those of the facet $\mathrm{F} 1$.

4) The difference shows consequently that the RCC is strongly influenced by the phenomenon of Vibro-compaction (vibration + pressure) and also that the positions of the coarse aggregates follow a privileged direction under the effect of the load pressure and the vibration.

\section{References}

1. Arquie, G. and Morel, G., Compaction, Eyrolles, 1988 (in French).

2. Zdiri, M., Ben Ouezdou, M., and Néji J., "Theoretical and Experimental Study of Roller Compacted Concrete Strength," Magazine of Concrete Research, MCR, DOI: 10.1680/ macr.2007.00002, Vol. 60, No. 7, 2008, pp. 469 474.

3. De Larrard, F., Concrete Mixing Proportioning - A Scientific Approach, Modern Concrete Technology, Series 9, Editors, E \& FN Spon, London, 1999.

4. Sedran, T. and de Larrard, F., RENE-LCPC: Software to Optimize the Mix-design, website: http://www.lcpc.fr/fr/presentation/organigramme/div_tgce/result/rene.php (Accessed April 2005).

5. Projet National Français BaCaRa (1988-1996), Roller Compacted Concrete, Presse ENPC France, 1996 (in French).

6. Neville, A. M., Properties of Concrete, 4th ed., Longman, UK, 1995.

7. Zdiri, M., Ben Ouezdou, M., and Abriak, N., "Measurement and Evaluation of the Elastic Modulus and the Poisson's Ratio of the RCC: Case of the Low Cement Proportioning," The Fifth Arab Congress on Materials Science (ACMS-V), Gabes Tunisia, 2007.

8. Gauthier, P. and Marchand, J., Conception and Implementation of the Roller Compacted Concrete Pavements in Québec, Association Béton Québec (ABQ), Canada, 2004 (in French). 